\title{
Functional Axonal Regeneration through Astrocytic Scar Genetically Modified to Digest Chondroitin Sulfate Proteoglycans
}

\author{
William B. J. Cafferty, ${ }^{\star}$ Shih-Hung Yang, ${ }^{\star}$ Philip J. Duffy, Shuxin Li, and Stephen M. Strittmatter \\ Program in Cellular Neuroscience, Neurodegeneration and Repair, Yale University School of Medicine, New Haven, Connecticut 06510
}

\begin{abstract}
Axotomized neurons within the damaged CNS are thought to be prevented from functional regeneration by inhibitory molecules such as chondroitin sulfate proteoglycans (CSPGs) and myelin-associated inhibitors. Here, we provide a transgenic test of the role of CSPGs in limiting regeneration, using the gfap promotor to express a CSPG-degrading enzyme chondroitinase $\mathrm{ABC}$ (ChABC) in astrocytes. Corticospinal axons extend within the lesion site, but not caudal to it, after dorsal hemisection in the transgenic mice. The presence of the gfap-ChABC transgene yields no significant improvement in motor function recovery in this model. In contrast, functionally significant sensory axon regeneration is observed after dorsal rhizotomy in transgenic mice. These transgenic studies confirm a local efficacy for reduced CSPG to enhance CNS axon growth after traumatic injury. CSPGs appear to function in a spatially distinct role from myelin inhibitors, implying that combination-based therapy will be especially advantageous for CNS injuries.
\end{abstract}

Key words: chondroitin sulfate; axon regeneration; spinal cord injury; traumatic injury; dorsal rhizotomy; proteoglycan

\section{Introduction}

Functional recovery from neurological trauma and pathologies, such as spinal cord injury (SCI), multiple sclerosis, stroke, and traumatic brain injury, is limited by the failure of CNS axons to grow through an inhibitory environment (McGee and Strittmatter, 2003; Harel and Strittmatter, 2006; Liu et al., 2006). Molecular analysis of the inhibitors present in the injured CNS have focused on two classes of proteins: the myelin-associated inhibitors Nogo-A, myelin-associated glycoprotein (MAG), oligodendrocyte myelin glycoprotein, and ephrin-B3; and the reactive gliosis-associated inhibitors of the chondroitin sulfate proteoglycan (CSPG) class. A glial scar forms at the site of CNS lesion almost immediately after damage (Berry et al., 1983; Fitch and Silver, 1997). Hypertrophic astrocytic processes enmesh the lesion site and deposit an inhibitory extracellular matrix consisting primarily of CSPGs (Levine, 1994; Davies et al., 1997, 1999; Fitch and Silver, 1997; Fitch et al., 1999; Asher et al., 2000; Tang et al., 2003). This tissue reaction results in the formation a dense complicated structure that is inhibitory to regenerating axons (Davies et al., 1997, 1999; Bradbury et al., 2002). Each CSPG molecule contains a central core protein to which long unbranched glucosaminoglycan (GAG) side chains containing chondroitin sul-

\footnotetext{
Received Aug. 24, 2006; revised Jan. 3, 2007; accepted Jan. 16, 2007.

This work was supported by research grants from the Christopher Reeve Paralysis Foundation, the Falk Medical Research Trust, and the National Institutes of Health (S.M.S.)

${ }^{*}$ W.B.J.C. and S.-H.Y. contributed equally to this work.

Correspondence should be addressed to Stephen M. Strittmatter, Department of Neurology, Yale University School of Medicine, P.0. Box 208018, New Haven, CT 06510. E-mail: stephen.strittmatter@yale.edu.

S.-H. Yang's present address: Division of Neurosurgery, Department of Surgery, National Taiwan University Hospital, Taipei, Taiwan.

DOI:10.1523/JNEUROSC1.5176-06.2007

Copyright $\odot 2007$ Society for Neuroscience $\quad$ 0270-6474/07/272176-10\$15.00/0
}

fate are attached covalently. The bacterial enzyme chondroitinase ABC (ChABC) liberates chondroitin sulfate GAGs from CSPG core proteins to render a more permissive substrate for axonal outgrowth in vitro (McKeon et al., 1995).

Both axonal growth and functional regeneration have been observed after infusion of ChABC via a CNS catheter into rodents with spinal cord or brain injury (Yick et al., 2000; Bradbury et al., 2002; Caggiano et al., 2005; Barritt et al., 2006). Pharmacological strategies that target myelin-associated inhibition (Schnell and Schwab, 1990; Bregman et al., 1995; Brosamle et al., 2000; Dergham et al., 2002; Fournier et al., 2002; GrandPre et al., 2002; Li and Strittmatter, 2003; Fouad et al., 2004; S. Li et al., 2004; W. $\mathrm{Li}$ et al., 2004) have provided results generally similar to those with ChABC infusion. However, gene-targeting loss-of-function studies for myelin-associated inhibitors such as Nogo-A and MAG or the NgR receptor have provided less clear results regarding the essential role of these proteins as inhibitors of axonal regeneration (Bartsch et al., 1995; Kim et al., 2003, 2004; Simonen et al., 2003; Zheng et al., 2003, 2005; Cafferty and Strittmatter, 2006; Dimou et al., 2006). Conflicting pharmacological and genetic results can be explained by either chronic compensatory changes in gene expression in genetic studies or off-target actions in pharmacological experiments. To the extent that off-target effects are a concern for myelin-associated inhibitors, they are at least as great a concern for $\mathrm{ChABC}$ studies because of the fact that $\mathrm{ChABC}$ is a protein extracted from bacteria. As such, it may contain impurities and may also elicit an immune response. No published work has used a gene-targeting or transgenic ( $\mathrm{Tg}$ ) methodology to reduce CSPG levels after CNS injury.

We sought to provide a transgenic analysis of CSPG action in limiting axonal growth and behavioral recovery from CNS injury. Here, we engineered transgenic mice to express $C h A B C$ under 
the gfap promoter and assessed the ability of damaged axons to regenerate through glial scars after dorsal hemisection and dorsal rhizotomy. Transgenic mice express functional enzyme in both lesion models, but the combination of axonal regeneration and enhanced behavioral recovery is only observed after dorsal rhizotomy. After dorsal hemisection, elevated numbers of growing corticospinal (CST) axons are observed in the glial scar, but transgenic mice show an insignificant recovery of function compared with wild-type littermates. Our transgenic data confirm a role for CSPGs in limiting the growth of primary sensory and corticospinal axons in the CNS after traumatic injury. The distinction between the pattern of axonal growth here and that after transgenic delivery of $\mathrm{NgR}(310)$ ecto (Li et al., 2005) emphasizes the possible advantages of combination therapy for CNS injury.

\section{Materials and Methods}

Generation of gfap::ChABC transgenic mice

The Proteus vulgaris ChABC cDNA (GenBank number E0825) was subcloned into the NotI site of the C-3123 vector containing the $2.0 \mathrm{~kb}$ murine gfap promoter (a kind gift from Dr. Lennart Mucke, Gladstone Institute of Neurological Disease, University of California, San Francisco, San Francisco, CA) (Johnson et al., 1995). This construct was released from the pGEM-11Z backbone by sequential digestion with AatII and Sfil, and the resulting $3.4 \mathrm{~kb}$ fragment was microinjected into embryos to generate transgenic mice. Transgene integration was verified by PCR, and four lines were identified. Two lines with the highest expression levels were crossed to C57BL/6J mice. Wild-type littermates were used as controls in all experiments.

\section{Surgical procedures}

Dorsal hemisection and corticospinal tract tracing procedure. Adult (4-6 months) female heterozygous transgenic mice $(n=10)$ or wild-type littermates $(n=10)$ were deeply anesthetized with intraperitoneal ketamine $(100 \mathrm{mg} / \mathrm{kg})$ and xylazine $(15 \mathrm{mg} / \mathrm{kg})$. A laminectomy was performed to expose the dorsal portion of spinal cord corresponding to T6 and T7 levels. The dura mater was pierced and the spinal cord was exposed, and a pledget of Gelfoam soaked in $1 \%$ lidocaine was placed on the exposed cord for $1 \mathrm{~min}$ before lesion. A dorsal over-hemisection lesion was performed at $\mathrm{T} 6$ with a 30 gauge needle and a pair of microscissors to a depth of $1.0 \mathrm{~mm}$ to completely sever the dorsal and dorsolateral corticospinal tract. The overlying muscle and skin was sutured with 4.0 vicryl. Concomitantly, mice received unilateral cortical injections with biotinylated dextran amine (BDA) to anterogradely label the corticospinal tract as described previously (Kim et al., 2003, 2004). Briefly, burr holes were made over the sensorimotor cortex, and four microinjections were made to a depth of $1.0 \mathrm{~mm}$ (coordinates, $0.5-1.5 \mathrm{~mm}$ posterior to bregma and $0.5-1.5 \mathrm{~mm}$ lateral to bregma) to deliver a total volume of $1.2 \mu \mathrm{l}$ of BDA (10,000 molecular weight; Invitrogen, Carlsbad, CA). Four weeks after dorsal hemisection, mice were perfused with $4 \%$ paraformaldehyde, postfixed overnight at $4^{\circ} \mathrm{C}$, and embedded in $10 \%$ gelatin for immunohistochemical processing.

Dorsal rhizotomy. Adult (4-6 months) female or male heterozygous transgenic mice $(n=18)$ or wild-type littermates $(n=12)$ were deeply anesthetized with intraperitoneal ketamine $(100 \mathrm{mg} / \mathrm{kg})$ and xylazine $(15$ $\mathrm{mg} / \mathrm{kg}$ ). A hemi-laminectomy was performed to expose the lateral portion of spinal cord corresponding to the $\mathrm{C} 4-\mathrm{T} 1$ spinal levels. The dura mater overlying dorsal roots $\mathrm{C} 5-\mathrm{C} 8$ was pierced just caudal to each individual root, fine (Dumont \#5) forceps were introduced subdurally between the dorsal root entry zone (DREZ) and dorsal root ganglia (DRG), and the dorsal roots were crushed by squeezing the forceps closed for $5 \mathrm{~s}$. Translucence of injured root demonstrated complete interruption at the time of injury, and histologic studies in control groups confirmed complete injury at follow-up. Muscle and skin were sutured with 4.0 vicryl. All animals recovered uneventfully. Twelve mice (acute group, $n=6$ transgenic, $n=6$ wild type), were killed $3 \mathrm{~d}$ after lesion, and 18 mice (chronic group, $n=12$ transgenic, $n=6$ wild type) were killed $21 \mathrm{~d}$ after lesion. Three days before perfusion, the chronic group received a $1 \mu \mathrm{l}$ microinjection of a $0.1 \%$ solution of cholera toxin $\beta$-subunit (CTB) (List
Biological Laboratories, Campbell, CA) in their left median nerve. All animals were transcardially perfused with $4 \%$ paraformaldehyde. Tissue was postfixed overnight and embedded in $10 \%$ gelatin for immunohistochemical possessing. All surgical procedures and postoperative care was performed in accordance with guidelines of the Yale University animal care and use committee.

\section{Behavioral analysis}

Mice that underwent over dorsal hemisection lesions were assessed using the Brief Motor Scale (BMS) (Basso et al., 2006). Mice that under went dorsal rhizotomy were split into two groups, and one group of 12 mice ( $n=6$ wild type, $n=6$ transgenic, acute group) were behaviorally assessed on days $-1,1,2$, and $3 \mathrm{~d}$ after lesion to confirm initial behavioral deficits in both genotypes of mice. A group of 18 mice were behaviorally assessed on days $-1,5,10,15$, and 20 after lesion (chronic group). All mice were subjected to two sensory tests, tape removal and thermal withdrawal. For tape removal, animals had an square of adhesive tape placed on the palmar surface of both of their forepaws, and the time taken to identify the tape (the "sense" component) and the time taken for the mice to remove the tape after sensing it (the "motor" component) was recorded once before lesion and on days 5, 10, 15, and 20 after lesion. For thermal testing, the forepaws of each animal were dipped into a $52^{\circ} \mathrm{C}$ water bath, and the time taken for them to withdraw their paws was recorded. Animals were tested once before surgery and on days 1, 2, 3, 5, 10,15 , and 20 after lesion by an experimenter blind to genotype. Behavioral responses of transgenic and wild-type mice were compared using two-way repeated-measures ANOVA, followed by Tukey's post hoc test.

\section{Immunohistochemistry}

Sagittal sections of dorsal hemisected thoracic spinal cord were processed to detect GFAP (antibody at 1:10,000; Invitrogen), chondroitin sulfate proteoglycans (CS56, 1:200; Sigma, St. Louis, MO), chondroitin-4sulfate (C4S, 1:1000; Chemicon, Temecula, CA), and BDA (avidin at 1:10,000; Invitrogen) and were visualized with appropriate secondary antibodies conjugated to AlexaFluor 488 and 546 (Invitrogen). The number of BDA-positive $\left(\mathrm{BDA}^{+}\right) \mathrm{CST}$ axons is presented as CST axon index, which is a ratio of the number of CST axons present at $-1,-0.5$, $-0.25,-0.1,0,0.5$, and $1 \mathrm{~mm}$ (relative to the lesion center) divided by the number of $\mathrm{BDA}^{+}$axons counted in the upper thoracic spinal cord. Assessment of astrocytic process orientation was achieved by counting the number of GFAP-immunoreactive (IR) processes that crossed the horizontal or vertical perimeters of defined areas in sagittal sections from wild-type and Tg-ChABC mice (supplemental Fig. 1, available at www. jneurosci.org as supplemental material). Twenty-five boxes of $20 \mu \mathrm{m}^{2}$ were superimposed on spinal cord montages in a $5 \times 5$ grid from the dorsal to ventral surface and from $1 \mathrm{~mm}$ rostral to $1 \mathrm{~mm}$ caudal from the lesion center.

Transverse sections of rhizotomized cervical spinal cord were processed to detect GFAP (antibody at 1:10,000; Invitrogen), chondroitin4-sulfate (antibody at 1:1000; Chemicon), small proline-rich protein 1A (SPRR1A) (antibody at 1:1000), calcitonin gene-related peptide (CGRP) (antibody at 1:16,000; Sigma), CTB (1:8000; List Biological Laboratories), and 4',6'-diamidino-2-phenylindole (DAPI) (dye at 1:10,000; Invitrogen). The average number of (SPRR1A-IR, CGRP-IR, or CTB-IR) regenerating axons was counted in five randomly selected sections containing the DREZ from each animal. The number of axons crossing a line perpendicular to the entering dorsal root is reported as a function of location at the PNS (0\% GFAP immunoreactivity) or CNS (100\% GFAP immunoreactivity) boundary of the DREZ.

\section{Results}

\section{Transgenic expression of chondroitinase $A B C$ in vivo}

A transgenic approach was used to reduce CSPG-mediated inhibition by injury-induced astroglial scars. The P. vulgaris ChABC cDNA was placed under the control of the murine gfap promoter (Fig. 1A). This promoter has been shown to faithfully drive astrocyte-selective expression of other transgenes and to do so most intensely at reactive CNS injury sites (Johnson et al., 1995; Li et al., 2005). Our transgenic construct included a signal se- 


\section{A gfap:::chondroitinase $A B C$}

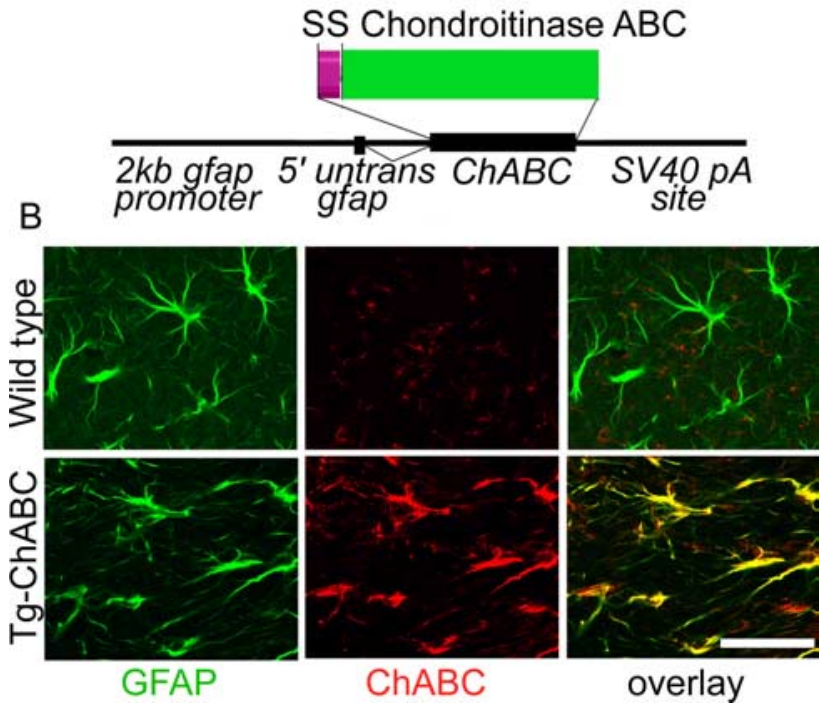

Figure 1. Transgenic expression of chondroitinase ABC. A, A schematic illustrates the DNA vector providing expression of $\mathrm{ChABC}$ under the control of the murine gfap promoter. Photomicrographs illustrate sections of motor cortex 2 weeks after stab lesion. Astrocytes in both wildtype and ChABC: 3 and Tg-ChABC:4 mice upregulate expression of GFAP (green). $\boldsymbol{B}$, An antibody that recognizes $\mathrm{ChABC}$ (red) shows 100\% overlap with GFAP (yellow) in transgenic mice. SV40, Simian virus 40 .

quence so that the recombinant protein would be targeted to the secretory pathway. Four lines of mice (Tg-ChABC: 1 to TgChABC:4) were established by injection of this DNA into fertilized eggs. We selected two lines, termed Tg-ChABC:3 and Tg-
ChABC:4, for additional investigation based on higher expression levels. Adult wild-type, Tg-ChABC:3, and TgChABC:4 mice underwent cortical stab injuries to create a gliotic lesion rich in reactive astrocytes (Fig. $1 B$ ). One week after lesion, immunohistochemical analysis reveals that GFAP-IR astrocytes from transgenic animals expressed anti-ChABC-IR protein.

\section{Transgenic chondroitinase $\mathrm{ABC}$ digests CSPGs after CNS trauma}

To confirm enzymatic activity of transgenic ChABC, adult wildtype and transgenic mice underwent either dorsal overhemisection spinal cord injury at T6 (Dhx) (Fig. 2) or dorsal rhizotomy of cervical dorsal roots C5-C8 (Rhx) (Fig. 3). Enzymatic digestion of endogenous and injury-upregulated CSPGs by transgenically expressed ChABC in vivo was assessed immunohistologically. The anti-chondroitin sulfate CS56 antibody recognizes CSPGs with intact GAG side chains. The anti-chondroitin4-sulfate $\mathrm{C} 4 \mathrm{~S}$ antibody detects the tetrasaccharride linker region, or stub, that results from $\mathrm{ChABC}$ action. CS56 immunoreactivity is observed throughout spinal gray and white matter of intact wild-type (Fig. 2A) and transgenic (Fig. $2 F, K$ ) mice. Thus, basal expression of transgenic ChABC is low and has no obvious effect on CSPG levels before injury. After Dhx, wild-type mice exhibit a pronounced increase in CS56 immunoreactivity at the lesion site, consistent with an injury-induced deposition of CSPGs (Fig. $2 B, C)$. As expected, no C4S-IR CSPG stubs are detected in Dhx wild-type mice (Fig. $2 D, E$ ). After Dhx, Tg-ChABC:3 (Fig. $2 G, H$ ) and Tg-ChABC:4 (Fig. $2 L, M$ ) mice show no detectable CS56 immunoreactivity within the GFAP-enriched lesion site. In contrast, the intense staining for C4S-IR stubs at the lesion site in Tg-ChABC:3 (Fig. $2 \mathrm{~J}, \mathrm{I}$ ) and Tg-ChABC:4 (Fig. 2 N,O)

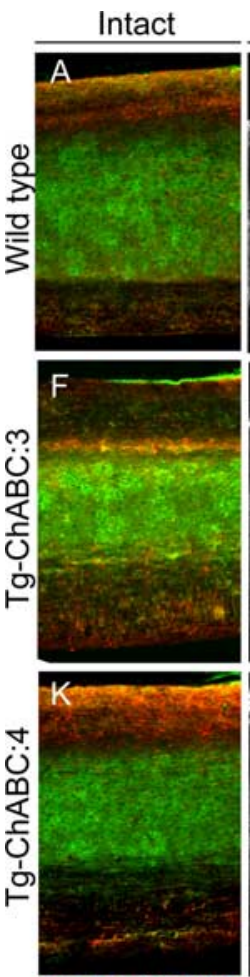

CS56 / GFAP
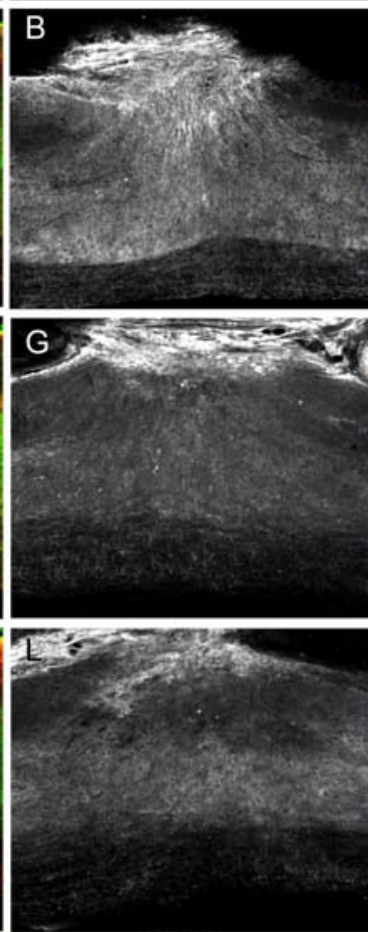

CS56
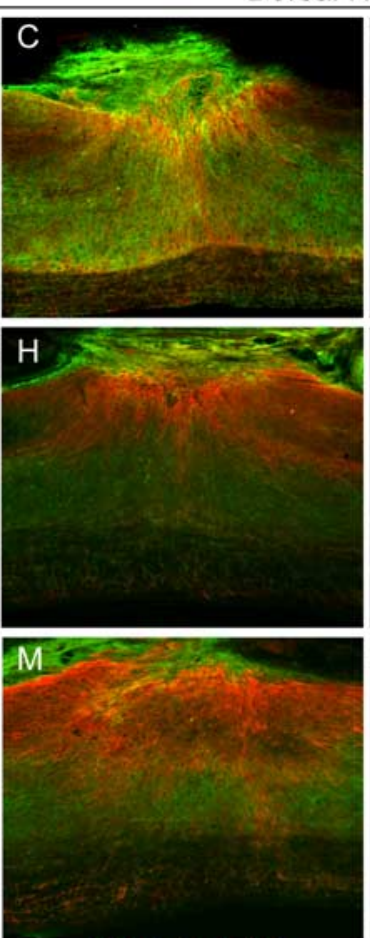

CS56 / GFAP
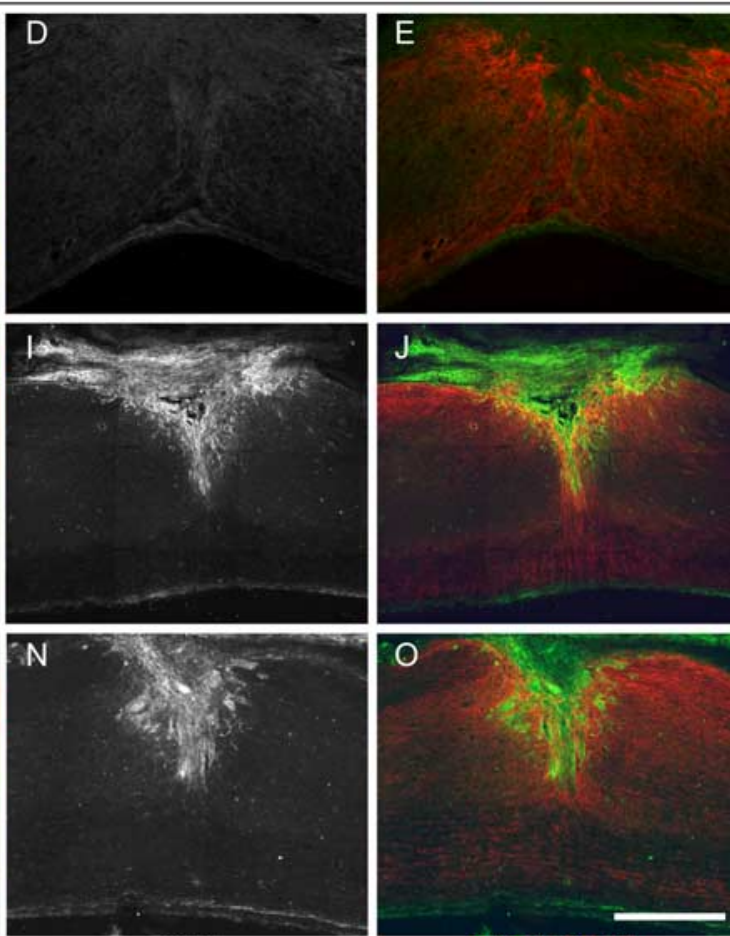

C4S

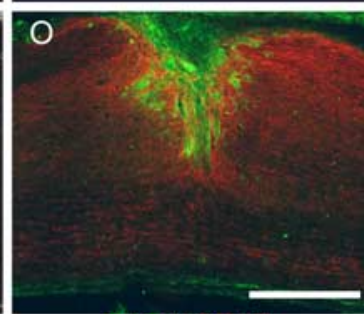

C4S / GFAP

Figure 2. Transgenic expression of functional $\mathrm{ChABC}$ after dorsal hemisection. Photomicrographs of sagittal sections from intact wild-type $(\boldsymbol{A}), \operatorname{Tg}-\mathrm{ChABC}: 3(\boldsymbol{F})$, and Tg-ChABC:4 $(\boldsymbol{K})$ mice show normal chondroitin sulfate proteoglycan (CS56-IR) deposition in spinal gray and white matter. Dorsal hemisection increases deposition of CS56-IR CSPGs at the lesion site of wild-type mice (B, $\boldsymbol{C}$ ). Chondroitin-4-sulfate immunoreactivity reflects $G A G$ degradation and is entirely absent from the lesion site $(\boldsymbol{D}, \boldsymbol{E})$. Dorsal hemisection in $\mathrm{Tg}$-ChABC:3 $(\boldsymbol{G}, \boldsymbol{H})$ and $\mathrm{Tg}$-ChABC:4 $(\boldsymbol{L}, \boldsymbol{M})$ shows no increase in CS56-IR CSPGs at the lesion site. Instead, there is robust C4S immunoreactivity of hydrolyzed CSPGs within the lesion site in Tg-ChABC:3 $(\boldsymbol{I}, \boldsymbol{J})$ and Tg-ChABC:4 $(\boldsymbol{N}, \mathbf{0})$ mice. Scale bar, $500 \mu \mathrm{m}$. 


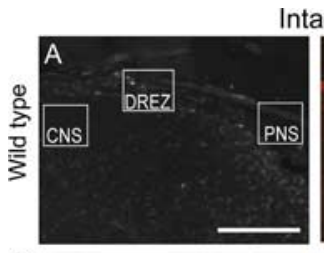

ntact
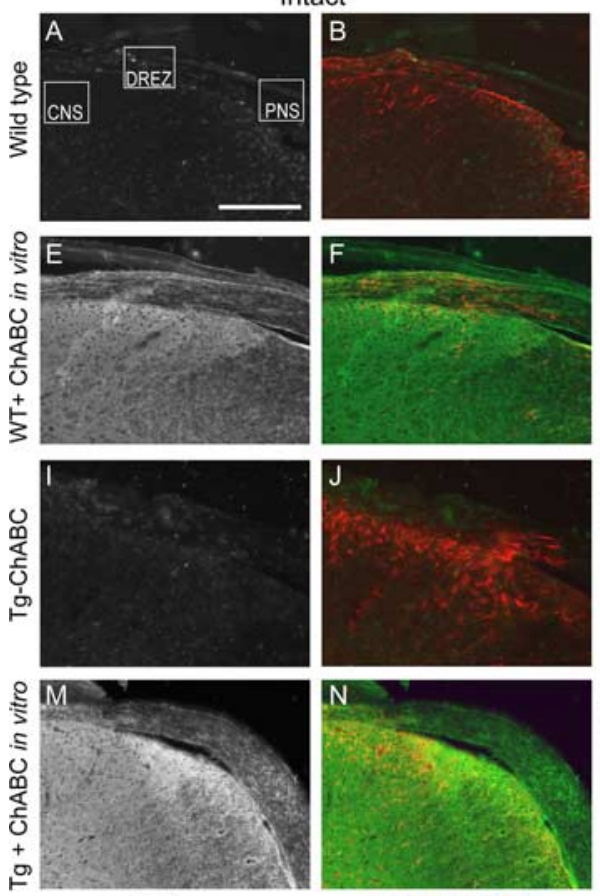

C4S

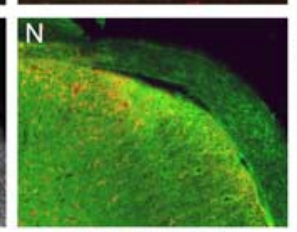

C4S / GFAP
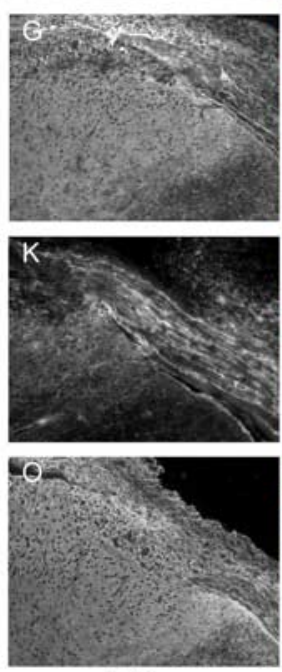

C4S

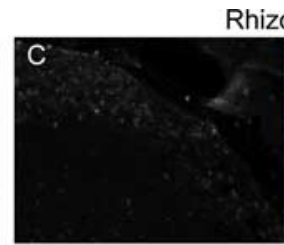

Rhizotomy
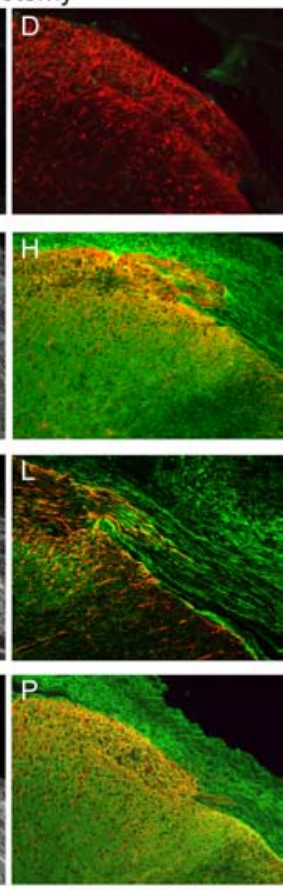

C4S / GFAP
Q

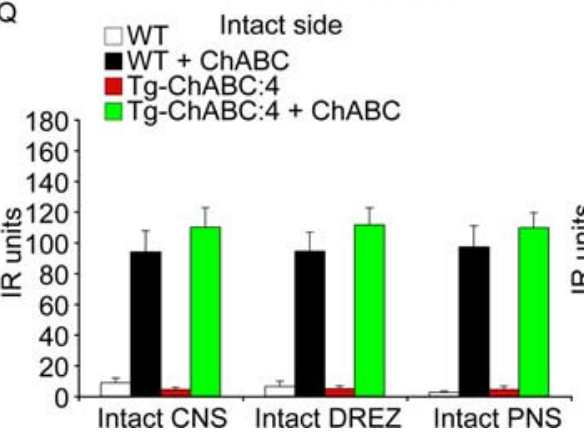

$\mathrm{R}$

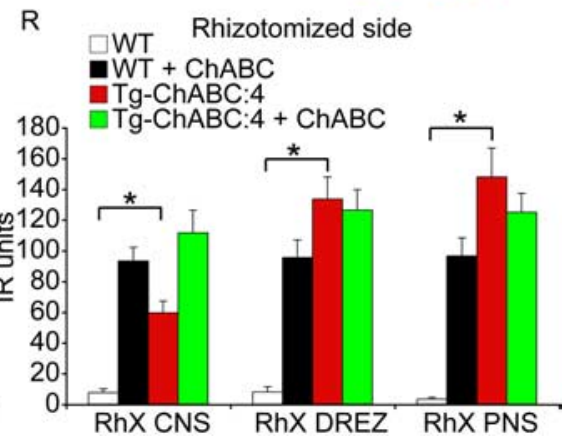

Figure 3. Transgenic expression of functional $C h A B C$ after dorsal rhizotomy. $\boldsymbol{A}-\boldsymbol{P}$, Photomicrographs show the DREZ from intact $(\boldsymbol{A}, \boldsymbol{B})$ and rhizotomized $(\boldsymbol{C}, \boldsymbol{D})$ wild-type (WT) plus intact $(\boldsymbol{I}, \boldsymbol{J})$ and rhizotomized $(\boldsymbol{K}, \boldsymbol{L}) \mathrm{Tg}$-ChABC mice. GFAP-IR astrocytes (red) extend into the damaged dorsal root in both lesioned wild-type $(\boldsymbol{C})$ and $\operatorname{Tg}$-ChABC $(\boldsymbol{L})$ mice. (4S-IR CSPG stubs are present in the damaged GFAP-rich DREZ of Tg-ChABC mice $(\boldsymbol{K}, \boldsymbol{L})$ but are entirely absent from wild-type mice $(\boldsymbol{C}, \boldsymbol{D})$. Sections from intact $(\boldsymbol{E}$, $\boldsymbol{F})$ and rhizotomized $(\boldsymbol{G}, \boldsymbol{H})$ wild-type and intact $(\boldsymbol{M}, \boldsymbol{N})$ and rhizotomized $(\boldsymbol{O}, \boldsymbol{P}) \mathrm{Tg}$-ChABC mice were treated in vitro with $\mathrm{ChABC}$ enzyme to digest all CSPGs and then stained with C4S to reveal maximum stub concentration. The optical density of C4S immunoreactivity in three areas (the CNS adjacent to the DREZ, the DREZ, and adjacent PNS; $A$ ) of rhizotomized and intact wild-type and $\mathrm{Tg}-\mathrm{Ch} A B C$ mice with and without in vitro $\mathrm{ChABC}$ treatment compares the relative efficacy of transgenic $\mathrm{Ch} A \mathrm{BC}$ expression versus subsequent digestion of CSPGs in vivo. Q, No significant difference in optical density of C4S immunoreactivity was observed within the CNS, DREZ, or PNS zones between wild-type and $\mathrm{Tg}-\mathrm{ChABC}$ mice without in vitro $\mathrm{ChABC}$ treatment. $\mathrm{ChABC}$ treatment increased the density of stubs 10 -fold in both wild-type and $\mathrm{Tg}$-ChABC mice equally ( $(\boldsymbol{Q})$ (data are mean \pm SEM). $\boldsymbol{R}$, 0 n the rhizotomized side, the optical density of stub staining is significantly higher in the CNS, DREZ, and PNS zones of Tg-ChABC mice compared with wild-type mice (data are mean $\pm \mathrm{SEM} ; p<0.001$, ANOVA). In vitro digestion of Drx sections reveals that transgenic expression of ChABC in vivo is highly efficient in digesting (SPGs near the DREZ (R). Scale bar, $200 \mu \mathrm{m}$.

mice indicates that the vast majority of CSPGs present after injury at the lesion site are hydrolyzed (for quantification, see next section). However, it is also critical to note that, although CSPG digestion is nearly complete locally, it is highly focal in the transgenic model. More than several millimeters from the center of the lesion, the extent of CSPG digestion is nil.

A dorsal root injury ( $\mathrm{Rhx}$ ) is known to induce the upregulation of GFAP in reactive astrocytes at the damaged DREZ. Hyperfilamentous astrocytic processes can be seen extending into the injured dorsal root in wild-type (Fig. $3 D, H$ ) and Tg-ChABC (Fig. $3 L, P$ ) mice after quadruple rhizotomy of C5-C8. C4S-IR stubs are absent from the DREZ of intact (Fig. $3 A, B$ ) and rhizotomized wild-type (Fig. $1 C, D$ ) mice, confirming the lack of CSPG degradation. Tg-ChABC mice show no detectable C4S-IR stubs at the intact DREZ (Fig. 3 $I, J$ ), again demonstrating that CSPG degradation is minimal in the transgenic mice without injury. In contrast, the transgenic mice exhibit dense C4S immunoreactivity at the lesioned DREZ after rhizotomy (Fig. $1 K, L$ ).

To assess the completeness of transgenic digestion of CSPGs in vivo, we compared the level of C4S-IR stubs after in vivo digestion with that obtained by incubation of sections with excess ChABC enzyme in vitro. Levels were determined in three areas (CNS adjacent to the DREZ, the DREZ, and the adjacent PNS) (Fig. $3 A$ ) of transverse sections from intact and rhizotomized wild-type (Fig. $3 A-D$ ) or Tg:ChABC (Fig. 3I-L) mice. These C4S-IR levels were compared with those in sections of intact and rhizotomized wild-type (Fig. $3 E-H$ ) or Tg:ChABC (Fig. 3M-P) mice treated in vitro with excess $\mathrm{ChABC}$ enzyme. The optical density of stub staining was not significantly different between wild-type and Tg-ChABC mice on the intact side in any of the three locations in the absence of in vitro ChABC treatment (Fig. $3 Q)$. Wild-type and Tg-ChABC mice treated in vitro with ChABC revealed similarly high C4S-IR stub density throughout the spinal parenchyma (Fig. 3Q). Rhizotomy-induced expression of C4S-IR stubs was higher in Tg-ChABC compared with wild-type mice (Fig. 3R) (ANOVA, $\left.{ }^{*} p<0.001\right)$ within the CNS, at the DREZ, and in the PNS. Most critically, within the CNS adjacent to the DREZ, transgenic digestion in vivo is at least $50 \%$ as effective at hydrolyzing CSPGs as is in vitro digestion (Fig. 3R). Within the DREZ and the PNS, transgenic in vivo and exogenous in vitro digestion produced essentially equal C4S immunoreactivity, demonstrating complete digestion for the transgenic mice in vivo (Fig. $3 R$ ). Thus, Tg-ChABC mice digest nearly all CSPGs present at sites of CNS injury to provide a robust transgenic model for assessing the role of focal CSPGs in limiting adult CNS axonal growth. CSPGs more than several millimeters distant from the injury site are not significantly degraded in the transgenic mice.

\section{Transgenic ChABC allows CST axons into scar tissue}

The rodent CST provides a useful system with which to study axonal regeneration and recovery of function after experimental spinal cord injury. The bulk of the CST runs in the ventral portion of the dorsal columns, with a minor but functionally significant component running in the lateral and ventral funiculi. Wild-type (Fig. 4A,B), Tg-ChABC:3 (Fig. 4C,D), and Tg-ChABC:4 (Fig. 
$4 E, F)$ mice received bilateral dorsal overhemisection lesions to ablate both dorsal and lateral CSTs. To accurately assess the pattern of CST axons, it is critical to verify that the underlying tissue architecture of the lesion is unaltered by the transgene. GFAP-IR processes are oriented across the cord near the lesion and longitudinally at more rostral and caudal sites (Fig. $4 A, C, E$ ) (supplemental Fig. 1, available at www.jneurosci.org as supplemental material). The presence of transgenic ChABC did not alter this arrangement (Fig. 4G).

CST fibers were labeled via cortical injections with the anterograde tracer BDA (Fig. 4A,C,E, green). CST axons can be seen approaching the lesion site in wildtype mice but abruptly stop $\sim 1 \mathrm{~mm}$ rostral to the lesion epicenter (Fig. $4 A, B$, asterisk). Tg-ChABC:3 and Tg-ChABC:4 mice show robust numbers of $\mathrm{BDA}^{+} \mathrm{CST}$ axons coursing into the lesion site. In transgenic mice, it is clear that CST axons extend into the highly GFAP-IR regions of lesion scar (Fig. 4C-F, yellow). Quantification of the number of CST axons within the lesion site revealed significantly greater numbers of axons for $\mathrm{Tg}$ ChABC: 3 and Tg-ChABC:4 mice than for wild-type controls (Fig. $4 H$ ). Such fibers may reflect either enhanced regeneration or reduced dieback of axons. Their highly branched profiles and the documentation of sensory axon regeneration (see below) suggest that CST axons regenerate in the lesion site of transgenic mice. Although elevated numbers of regenerating CST axons were present rostral to the lesion site, no CST axons were observed caudal to the lesion. Open-field locomotor scores (BMS) revealed a trend toward improved behavioral recovery in the transgenic mice, but this did not reach statistical significance and was not apparent at later time points (Fig. 4I).

\section{Sensory axon regeneration after dorsal rhizotomy}

A second CNS regeneration model was studied to determine the extent of inhibition of primary sensory axons by CSPGs within focal astrocytic scars. After dorsal root injury of wild-type animals, axonal regeneration proceeds with high fidelity through the PNS zone but is abruptly arrested at the DREZ, separating the PNS from the CNS (Fig. 5A-I, labeled with GFAP, red). Adult mice received unilateral quadruple dorsal root crush lesions (rhizotomies) from $\mathrm{C} 5-\mathrm{C} 8$, inclusively. This lesion axotomized the central branches of all sensory neurons entering the spinal cord through these spinal segments and results in a deficit of forelimb sensory function ipsilaterally. Animals were killed for histology either 3 or $20 \mathrm{~d}$ after lesion to assess axon regeneration. GFAP-IR astrocytic processes are prominent in the CNS zone at the DREZ adjacent to an injured dorsal root in both wild-type (Fig. $5 A, C, F, H)$ and Tg-ChABC (Fig. $5 B, D, G, I)$ mice.

Regenerating axons were identified by their elevated expression of the growth-associated protein SPRR1A (Bonilla et al., 2002). Although there is no SPRR1A in naive mice, gene induc-
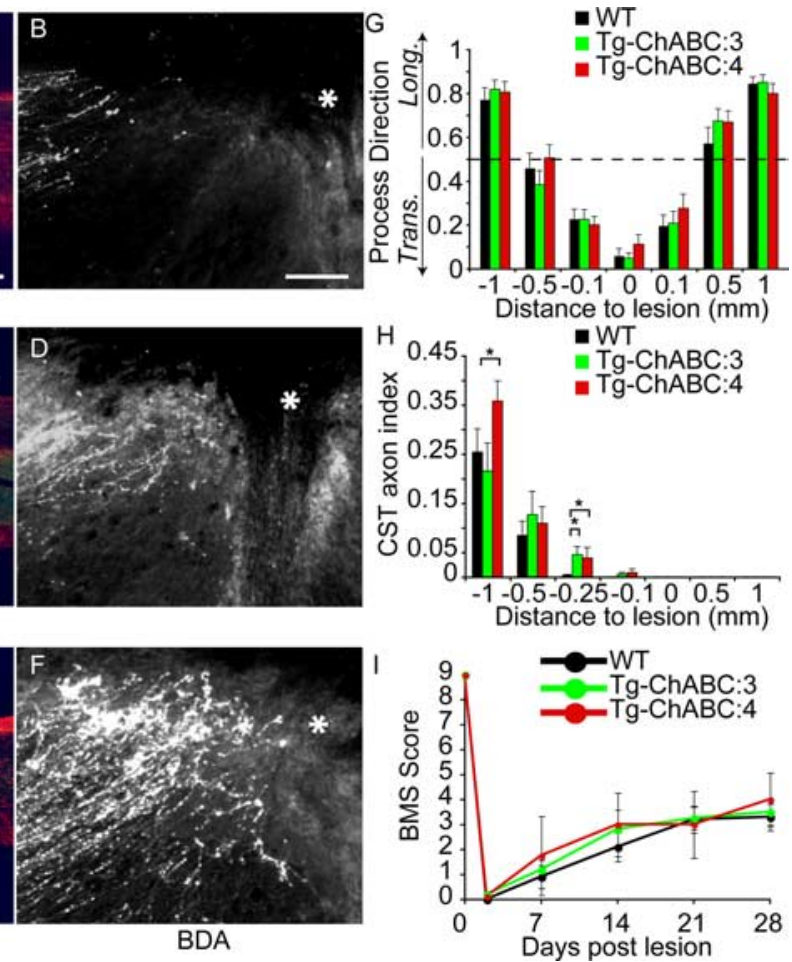

28

Figure 4. Transgenic ChABC increases the number of CST axons in astrocytic scar of a SCl. $\boldsymbol{A}-\boldsymbol{F}$, Photomicrographs illustrate sagittal sections of wild-type (WT) $(\boldsymbol{A}, \boldsymbol{B}), \mathrm{Tg}-\mathrm{ChABC}: 3(\boldsymbol{C}, \boldsymbol{D})$, and $\mathrm{Tg}$-ChABC:4 $(\boldsymbol{E}, \boldsymbol{F})$ mice 4 weeks after bilateral dorsal over列

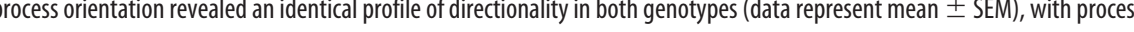
Wild-type, $\mathrm{Tg}$-ChABC:3, and $\mathrm{Tg}$-ChABC:4 mice underwent open-field locomotion assessment after dorsal over-hemisection;

tion occurs within intact motor neurons of the same segmental level and DRG neurons of adjacent spinal levels attributable to tracer injections into the median nerve and surgical traction on ventral roots. However, those SPRR1A-IR structures that are observed deep in the spinal cord parenchyma are clearly separate from the SPRR1A fibers induced in the rhizotomized dorsal root. SPRR1A-IR axons are observed to extend up to the damaged DREZ in wild-type (Fig. $5 A, C$ ) and Tg-ChABC (Fig. $5 B, D$ ) mice $3 \mathrm{~d}$ after lesion (Fig. $3 A, C$ ). However, no axons were apparent central to the DREZ (Fig. $5 E$ ) at this time point. Assessment of animals $20 \mathrm{~d}$ after lesion revealed that regeneration of SPRR1A-IR sensory axons through the GFAP-free peripheral region of the root in Tg-ChABC (Fig. 5G,I) is indistinguishable from that in wild-type (Fig. $5 F, H)$ mice. In the wild-type mice, no SPRR1A-IR fibers cross the DREZ into the CNS. However, many regenerating SPRR1A-IR axons traverse the DREZ and enter the spinal cord gray matter of rhizotomized Tg-ChABC:3 and Tg-ChABC:4 mice (Fig. $5 J$ ). Thus, transgenic digestion of CSPGs is sufficient to promote growth of sensory axons through the damaged DREZ and into the CNS environment.

\section{Recovery of nociceptive function after rhizotomy}

Sensory neurons are a heterogeneous population of cells that mediate multiple sensory modalities. To identify the modality of the SPRR1A-IR axons that had regenerated into the spinal cord, we focused on two different populations of cells, nociceptors and 

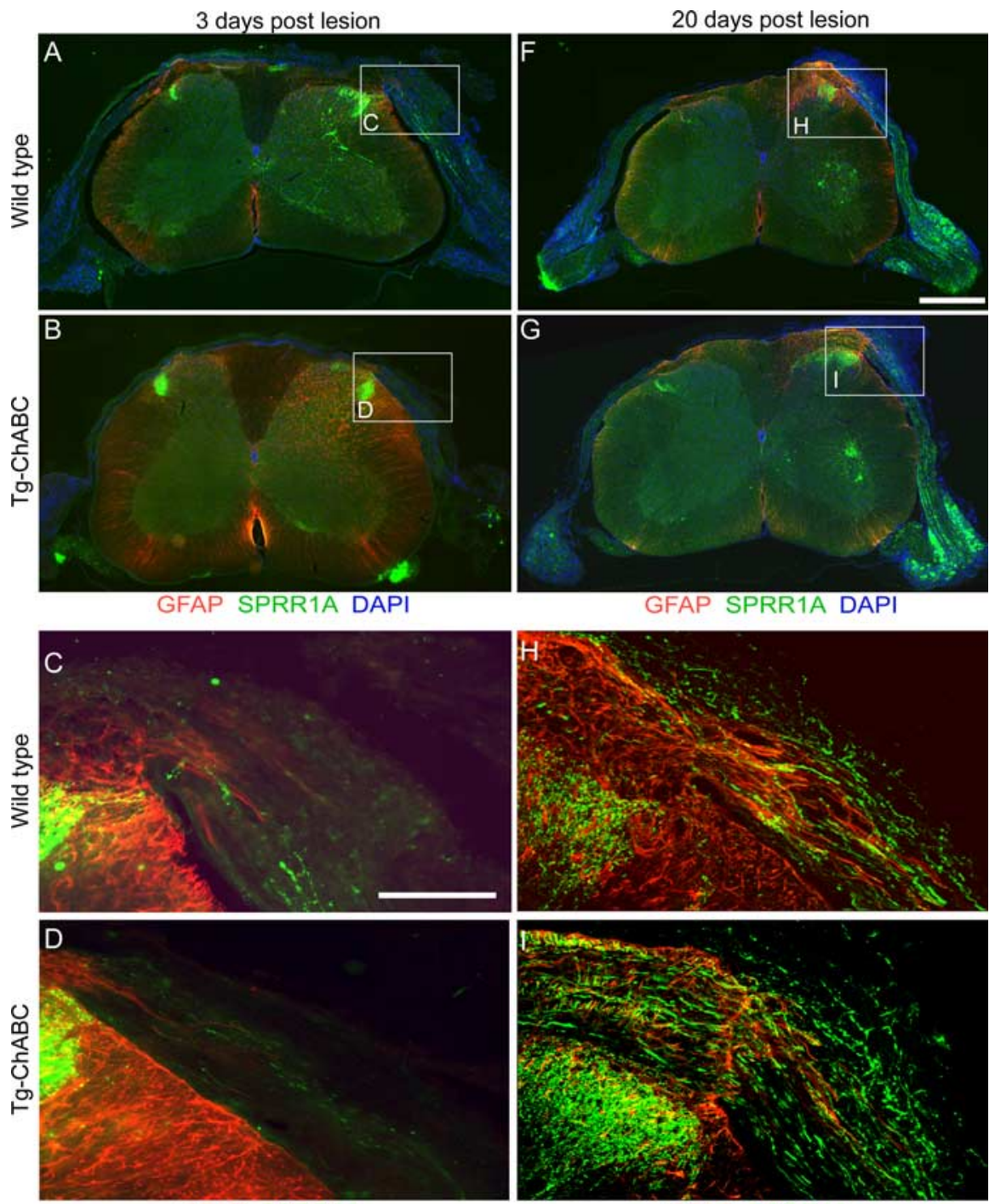

GFAP SPRR1A

E

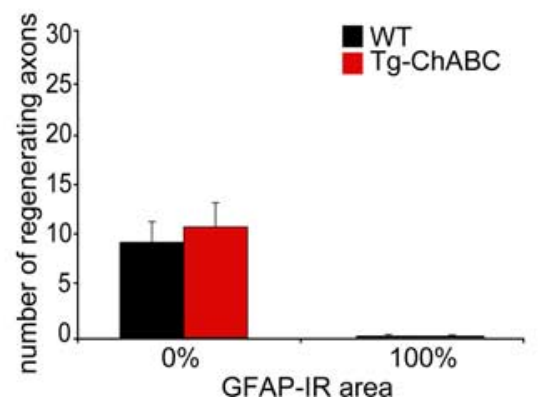

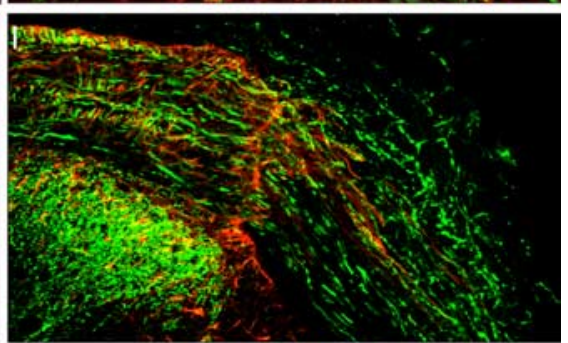

GFAP SPRR1A

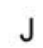

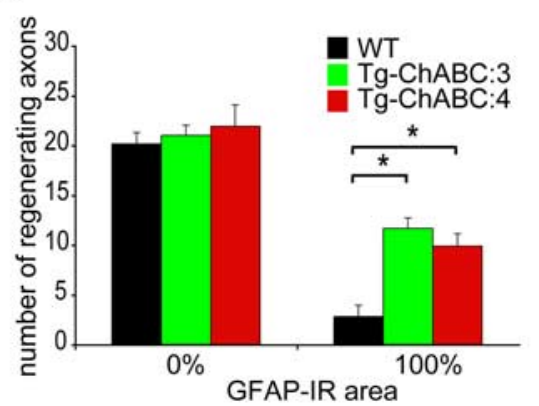

Figure 5. Transgenic expression of $\mathrm{ChABC}$ promotes regeneration of sensory neurons after dorsal rhizotomy. $A-D, F-I$, Photomicrographs illustrate transverse section of cervical spinal cord from adult wild-type (WT) $(\boldsymbol{A}, \boldsymbol{F})$ and $\mathrm{Tg}$-ChABC $(\boldsymbol{B}, \boldsymbol{G})$ mice that had undergone unilateral rhizotomy from $C 5-C 83 \mathrm{~d}(\boldsymbol{A}-\boldsymbol{D})$ or $20 \mathrm{~d}(\boldsymbol{F}-\boldsymbol{I})$ after lesion (intact root left side, rhizotomized root right side; red, GFAP; green, SPRR1A; blue, DAPI). E, Insets show high-power photomicrographs of the rhizotomized DREZ. Three days after lesion, modest numbers of SPRR1A-IR (green) regenerating axons can be seen approaching the damaged DREZ (delineated by GFAP-IR astrocytes; red) in both wild-type $(\boldsymbol{C})$ and $\mathrm{Tg}$-ChABC (D) mice; no SPRR1A-IR regenerating axons were seen central to the DREZ ( $\boldsymbol{E}$ ) (data represent mean \pm SEM axons; $x$-axis demarcates PNS from CNS by GFAP staining; $0 \%$ GFAP-IR refers to the PNS; $100 \%$ GFAP-IR refers to the (NS). $\boldsymbol{F}, \boldsymbol{H}, \boldsymbol{J}$, Twenty days after lesion, SPRR1A-IR axons can be seen throughout the dorsal root in wild-type mice $(\boldsymbol{F}, \boldsymbol{H})$, but few axons penetrate the DREZ and enter the spinal cord $(\boldsymbol{H}, \boldsymbol{J})$. In contrast, significant numbers of SPRRTA-IR axons can be seen growing up to and past the DREZ and entering the spinal cord in Tg-ChABC:3 and Tg-ChABC:4 mice $(\boldsymbol{I}, \boldsymbol{J})$ (data represent mean \pm SEM; ${ }^{*} p<0.001$, one-way ANOVA). Scale bars: $\boldsymbol{A}, \boldsymbol{B}, \boldsymbol{F}, \mathbf{G}, 500 \mu \mathrm{m} ; \boldsymbol{C}, \boldsymbol{D}, \boldsymbol{H}, \boldsymbol{I}, 100 \mu \mathrm{m}$.

proprioceptors. Nociceptors are smalldiameter thinly or unmyelinated sensory neurons whose central branches enter the spinal cord through the DREZ in fasciculated bundles and terminate in the superficial dorsal horn. One population of nociceptive neurons can be identified by virtue of their intrinsic expression of neuropeptides, such as CGRP. Regenerating CGRP-IR axons are seen approaching the damaged DREZ in wild-type mice (Fig. $6 A-C$ ), but axonal projections halt on reaching GFAP-IR astrocytes (CGRP, green; GFAP, red), with very few axons entering the spinal cord (Fig. 6G). In contrast, significant numbers of CGRP-IR axons can be seen growing up to and beyond the DREZ in Tg-ChABC (Fig. 6D-G).

The anatomical regeneration observed in $\mathrm{Tg}$-ChABC mice after rhizotomy may or may not subserve a return of neurological functions. To assess the contribution of transgene-dependent axon regeneration to mouse performance, we performed a thermal withdrawal test. The time taken for wild-type, Tg-ChABC:3, and TgChABC: 4 mice to withdraw their forepaws from a $52^{\circ}$ water bath was recorded before lesion and on days 1, 2, 3, 5, 10, 15, and 20 after lesion (Fig. 6H,I). Rhizotomized wild-type mice exhibit a significant increase in withdrawal latency up to $5 \mathrm{~d}$ after lesion, but their ability to integrate thermal stimulus returns to normal (indistinguishable from contralateral, intact forelimbs) by $10 \mathrm{~d}$ after lesion (Fig. $6 H, I$ ). The late improvement in sensitivity is not mediated by axonal regeneration but may occur via hypersensitivity and/or spinal rearrangements of spared spinal axons (Abad et al., 1989; Darian-Smith, 2004; Ramer et al., 2004). In contrast to wild-type mice, rhizotomized Tg-ChABC:3 and TgChABC:4 mice recover nociceptive function at least $5 \mathrm{~d}$ before wild-type controls (Fig. 4H,I). Thus, nociceptive axon growth is correlated with improved nociceptive performance in the rhizotomized transgenic mice at early time points.

\section{Recovery of cutaneous mechanical sensation after rhizotomy}

Large-diameter sensory neurons can be specifically labeled by virtue of their ability to transport CTB. We sought to investigate whether the regeneration of this population of cells is influenced by the transgenic expression of ChABC after dorsal rhizotomy. Regenerating CTB-IR axons are seen approaching the damaged DREZ in wild-type mice (Fig. 7A), but regenerating axons stop abruptly on reaching GFAP-IR astrocytes (CTB, green; GFAP, 

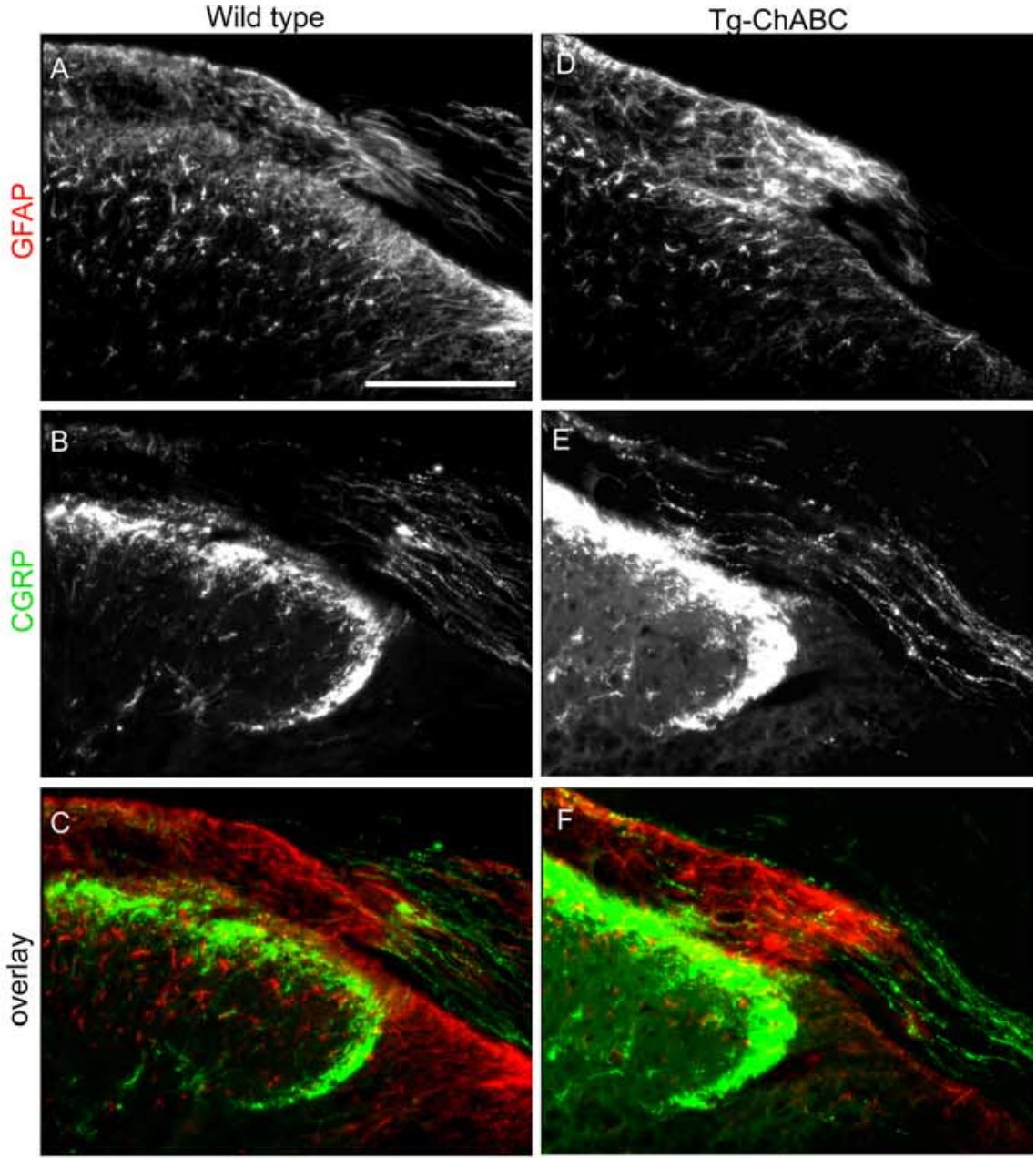

G
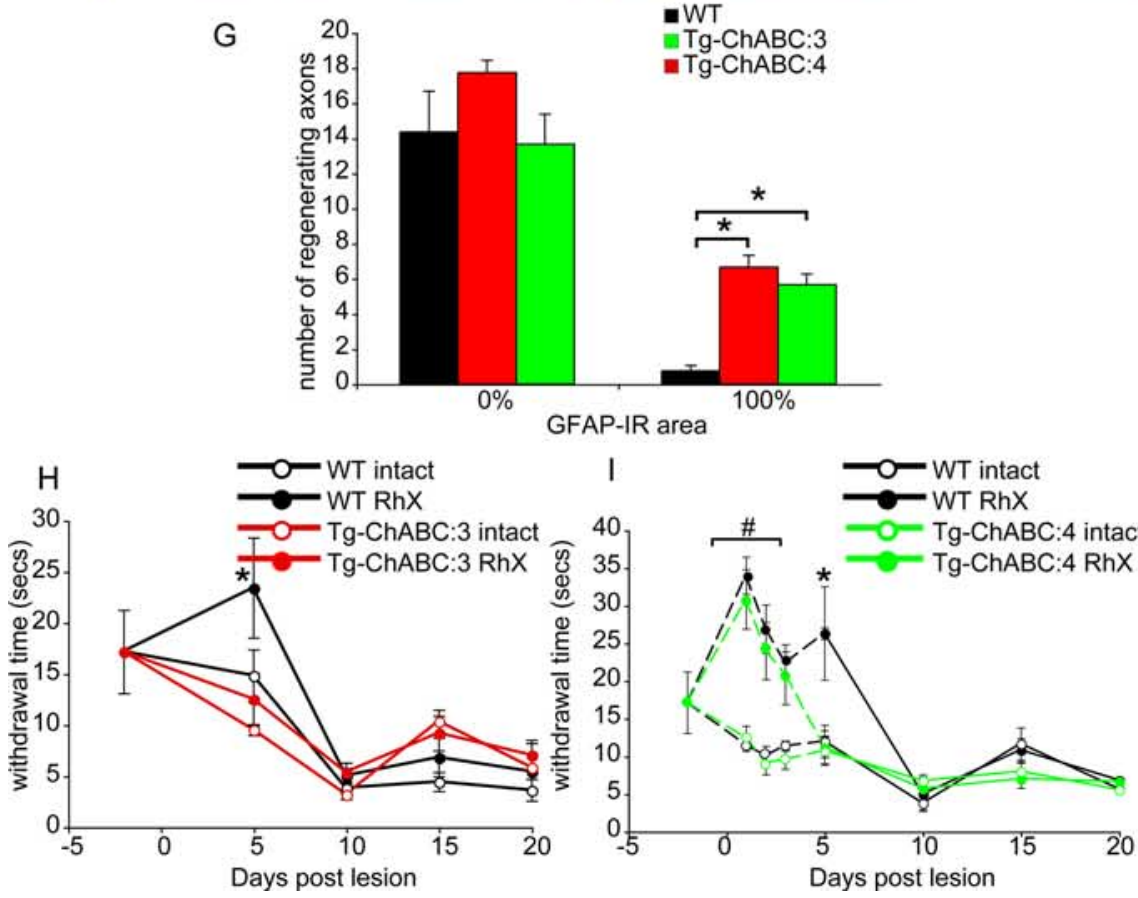

Figure 6. Transgenic expression of $\mathrm{Ch} A B C$ restores nociceptive function after dorsal rhizotomy. $\boldsymbol{A}-\boldsymbol{F}$, Photomicrographs illustrate transverse section of ipsilateral $C 7$ spinal cord from wild-type (WT) $(\boldsymbol{A}-\boldsymbol{C})$ and $\mathrm{Tg}$-ChABC $(\boldsymbol{D}-\boldsymbol{F}) 21 \mathrm{~d}$ after dorsal rhizotomy. GFAP-IR astrocytes bulge into the PNS in both wild-type $(\boldsymbol{A}, \boldsymbol{C})$ and $\mathrm{Tg}$-ChABC:3 $(\boldsymbol{D}, \boldsymbol{F})$ mice. Regenerating CGRP-IR axons abruptly stop growing when they reach the damaged DREZ in wild-type mice ( $\boldsymbol{B}, \boldsymbol{C})$. G, CGRP-IR axons traverse the damaged DREZ in Tg-ChABC mice $(\boldsymbol{E}, \boldsymbol{F})$ and reenter the spinal cord. Quantification of the number of CGRP-IR axons at the DREZ ( $x$-axis demarcates PNS from CNS by GFAP staining; 0\% GFAP-IR refers to the PNS; 100\% GFAP-IR refers to the CNS) shows Tg-ChABC:3 and Tg-ChABC:4 red), with very few axons entering the spinal cord (Fig. 7C). In contrast, significant numbers of CTB-IR axons can be seen growing up to and beyond the DREZ in Tg-ChABC (Fig. $7 B, C$ ).

These sensory fibers mediating cutaneous mechanical sensation and can be assessed experimentally by recording the time taken for mice to sense the presence of and remove a small piece of adhesive tape from their forelimbs. Time taken for animals to sense the presence of adhesive tape placed on both ipsilateral and contralateral forelimbs and time taken to remove the tape was recorded before lesion and on days $1,2,3,5,10,15$, and 20 after lesion (Fig. $7 D, E$ ). Wild-type mice illustrate a significantly increased time in sensing the adhesive tape on their ipsilateral (rhizotomized) paws after lesion, in contrast to contralateral intact wild-type and transgenic controls $\left({ }^{*} p<0.05\right.$, two-way repeated-measures ANOVA). This sensory deficit is maintained throughout the testing period. In contrast, both $\mathrm{Tg}$ ChABC:3 (Fig. 3H) and Tg-ChABC:4 (Fig. 3I) mice show a significant recovery in their ability to sense the presence of the adhesive tape by $4 \mathrm{~d}$ after lesion compared with injured wild-type mice (two-way repeated-measures ANOVA). Time taken to sense tape on contralateral paws remains constant throughout the testing period. Motor scores (time taken to remove tape) are not significantly different between ipsilateral and contralateral paws from wild-type or transgenic mice (data not shown).

\section{Discussion}

This study provides transgenic evidence that CSPGs limit axonal growth in the CNS after traumatic injury. The expression of ChABC by reactive astrocytes effectively degrades CSPGs in glial-scarred tissue and allows CST and DRG axon

\section{$\leftarrow$}

to have significantly more axons entering the spinal cord compared with wild-type control mice (data represent mean \pm SEM; ${ }^{*} p<0.001$, one-way ANOVA). $\boldsymbol{H}$, I, Thermal withdrawal latencies were recorded from wild-type (black lines), $\mathrm{Tg}-\mathrm{ChABC}: 3$ ( $\boldsymbol{H}$, red lines), and $\mathrm{Tg}-\mathrm{ChABC}: 4$ (I, green lines) mice to assess return of nociceptive function after rhizotomy. Withdrawal latency was significantly elevated ipsilateral to the lesion after rhizotomy in wild-type (filled black circles) and Tg-ChABC (filled red and green circles) mice compared with their contralateral intact sides (open circles, $\boldsymbol{H}, \boldsymbol{I}$ ) (data represent mean \pm SEM withdrawal time; ${ }^{\#} p<0.05$, one-way ANOVA). Wild-type mice recovered thermal sensation within $10 \mathrm{~d}$ of lesion. $\mathrm{Tg}-\mathrm{Ch} A \mathrm{BC}: 3$ and $\mathrm{Tg}-\mathrm{ChABC}: 4$ recovered significant thermal sensory function by $5 \mathrm{~d}$ after lesion $\left({ }^{*} p<0.05\right.$, one-way ANOVA) 5 d earlier than wild-type controls. Scale bar, $100 \mu \mathrm{m}$. 

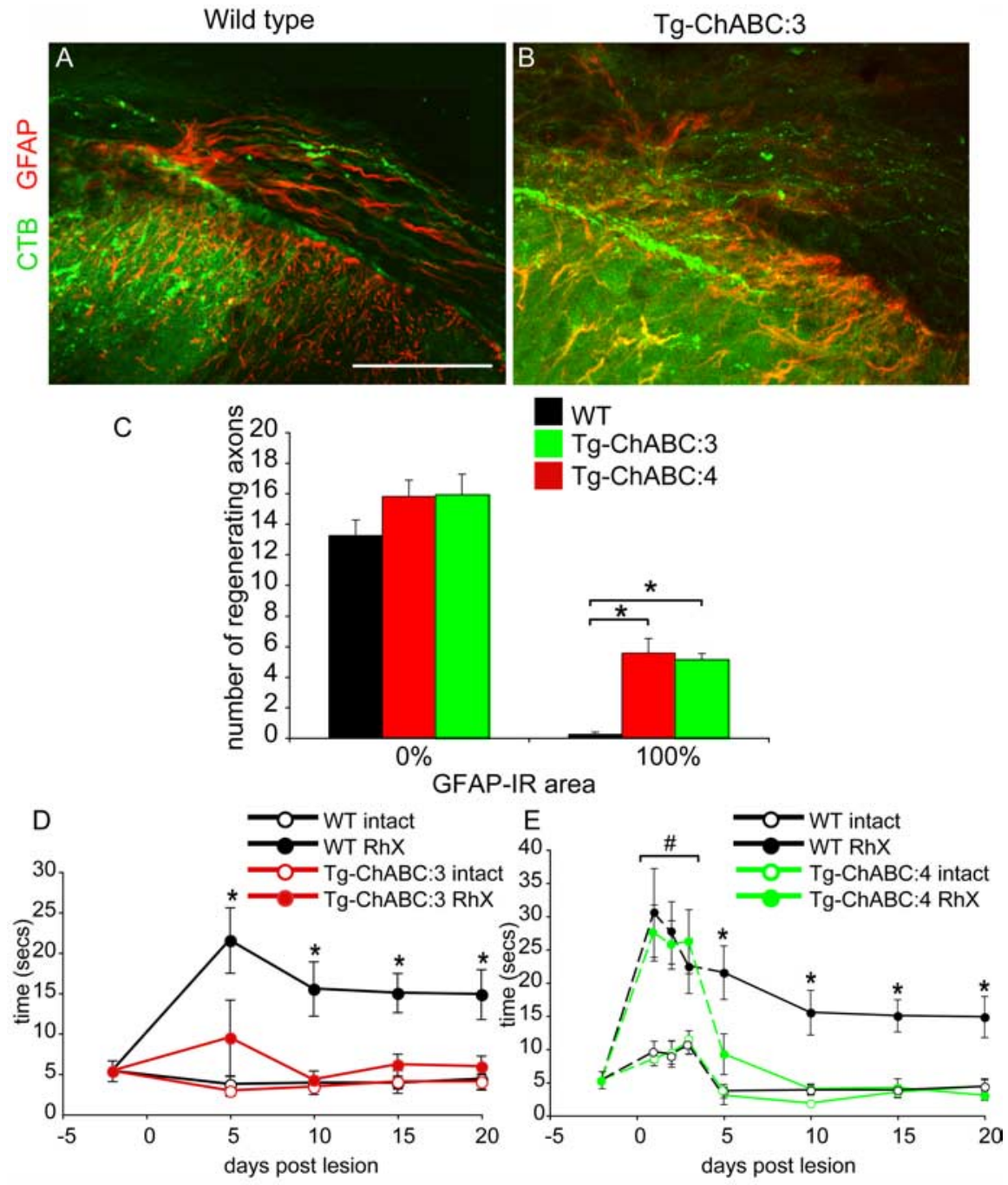

Figure 7. Transgenic expression of $\mathrm{ChABC}$ restores cutaneous mechanosensation after dorsal rhizotomy. $\boldsymbol{A}, \boldsymbol{B}$, Photomicrographs illustrate transverse sections of ipsilateral C7 spinal cord from wild-type (WT) $(\boldsymbol{A})$ and Tg-ChABC (B) $21 \mathrm{~d}$ after dorsal rhizotomy. The DREZ is demarcated by the presence of GFAP-IR reactive astrocytes (red); regenerating (TB-IR axons abruptly stop growing when they reach the damaged DREZ in wild-type mice (green, $A$ ). CTB-IR axons traverse the damaged DREZ in Tg-ChABC mice and reenter the spinal cord (green, $\boldsymbol{B})$. $\boldsymbol{C}$, Quantification of the number of CTB-IR axons at the DREZ ( $\boldsymbol{C}$ ( $(x$-axis demarcates PNS from CNS by GFAP staining; $0 \%$ GFAP-IR refers to the PNS; $100 \%$ GFAP-IR refers to the CNS) shows Tg-ChABC:3 and Tg-ChABC:4 to have significantly more axons entering the spinal cord compared with wild-type control mice (data represent mean $\pm S E M ;{ }^{*} p<$ 0.001 , one-way ANOVA). Mechanosensation of injured mice was assessed using a modified tape removal task. $D, E$, Sense assessment was significantly elevated ipsilateral to the lesion after rhizotomy in wild-type (filled black circles) and Tg-ChABC (filled red and green circles) mice compared with their contralateral intact sides (open circles) (data represent mean \pm SEM withdrawal time; ${ }^{\#} p<0.05$, one-way ANOVA). Wild-type mice maintained a deficit throughout the testing period, but $\operatorname{Tg}-\mathrm{ChABC}: 3$ and $\mathrm{Tg}$-ChABC:4 mice recovered significant function by $5 \mathrm{~d}$ after lesion $\left({ }^{*} p<0.05\right.$, one-way ANOVA) compared with rhizotomized wild-type mice. Scale bar, $100 \mu \mathrm{m}$.

growth in the damaged CNS. Such growth is associated with functional recovery after multiple level cervical dorsal rhizotomies but not after thoracic dorsal hemisection.

Previous studies using pharmacological delivery of ChABC alone after SCI have shown significant axon growth and/or functional recovery (Yick et al., 2000; Bradbury et al., 2002; Caggiano et al., 2005; Barritt et al., 2006). Akin to these studies with infusion of bacterial protein, we observed a significant encroachment of CST axons into the glial scar, but we failed to observe regeneration of axons across the lesion or a return of significant motor function. Because CSPG digestion at the injury site was nearly complete in our transgenic studies, ineffective ChABC action cannot provide the explanation for these differences. The lack of recovery might be a consequence of the nature and severity of the lesion, the tract under investigation, or off-target effects with pharmacological studies. Bradbury and colleagues used a dorsal column injury paradigm that specifically ablates ascending gracile and cuneate primary afferent collaterals and a significant portion of the CST (dorsal CST) (Bradbury et al., 2002; Barritt et al., 2006). This lesion spares the lateral and ventral CST and spinal gray matter, providing a greater expanse of less hostile tissue through which regenerating axons might grow after exposure to ChABC than does the dorsal overhemisection injury here. A segment of relatively permissive tissue might also exist in the study by Yick et al. (2000), which used a lateral hemisection paradigm. The same cannot be true in the severe compression injury study (Caggiano et al., 2005). Although that study comprehensively confirmed the efficacy of infused ChABC for enhancing motor and autonomic function, axonal regeneration was not examined. Together, these studies suggest that that injury severity alone cannot explain the limited efficacy of transgenically expressed $\mathrm{ChABC}$ in promoting longdistance CST regeneration and motor recovery after Dhx.

A more likely explanation for variable results may be the spatial distribution of ChABC action. The Bradbury and Caggiano studies delivered ChABC via an intrathecal cannula placed subdurally. Under these circumstances, ChABC may travel throughout the thecal space to influence distant intraspinal circuits that might assist in recovery of function (Bareyre et al., 2004). As can be seen in Figure 2, ChABC expression and subsequent CSPG digestion in our study is limited to a restricted penumbra of tissue at the lesion site and therefore cannot influence distal regions of the nervous system. Similarly, a recent study by Houle et al. (2006) demonstrated an efficacy for local application of ChABC to enhance the regeneration of spinal axons into the spinal cord from a peripheral nerve graft circumventing a dorsal hemisection injury. Thus, the promotion of axonal growth may be limited specifically to regions of tissue with active ChABC. Furthermore, enhanced long-distance axonal growth and motor recovery after SCI may require widespread CSPG removal. Treating distal intact tissue may as crucial as treating local astroglial scar domains.

Using a paradigm parallel to that of the current study, Li et al. (2005) observed long-distance functional regeneration of CST and raphespinal axons after dorsal hemisection in gfap:: $\mathrm{NgR}(310)$ ecto transgenic mice. These NgR results differ from the current study in two important ways. First, Li et al. observed numerous CST axons circumventing scarred tissue and 
extending some distance caudal to the lesion site, although we failed to observe long-distance regeneration of CST axons here. Second, the gfap::NgR(310)ecto mice did not exhibit significant axon growth into scarred tissue, whereas robust numbers of CST axons can be clearly seen within the lesion site in this study. This comparison reveals an important distinction between two interventions enhancing axon regeneration. Focal delivery of $\mathrm{NgR}(310)$ ecto is more efficacious than focal delivery of ChABC at encouraging long-distance regeneration of CST axons, but the latter results in greater localized sprouting of damaged axons into scarred tissue after Dhx. Such ChABC-dependent growth within scarred areas may be of equal or greater functional benefit under different circumstances, such as dorsal root avulsion injuries.

In light of this conclusion, we assessed the ability of transgenically expressed $\mathrm{ChABC}$ to encourage the localized regeneration of axons through a more discrete astrocytic lesion. Dorsal root lesion results in permanent retraction of primary afferents from their terminals in the spinal cord. A frequent complication of such injuries in humans is the emergence of chronic neuropathic pain states and a persistent loss of sensation in the affected dermatome (Htut et al., 2006). Most commonly, these injuries occur as a result of brachial plexus avulsions associated with whiplash and traction of limbs during motor-vehicle accidents or ballistic injuries. The current lack of applicable therapy for these patients highlights an urgent unmet clinical need.

Previous studies that have addressed rhizotomy-induced loss of function have focused primarily on the damaged axons either by boosting their growth capacity pharmacologically (Ramer et al., 2000) or virally by delivering neurotrophic factors (Romero et al., 2001) or providing them with a alternative growth substrate in the form of transplanted olfactory ensheathing glial cells (OEGs) (Ramon-Cueto et al., 2000). Although successful, these approaches have caveats. Large doses of neurotrophic factors may cause aberrant effects on intact pathways that also express Trk receptors (for review, see Pezet and McMahon, 2006). Furthermore, sensory neurons express disparate Trk receptors that would ultimately require a mixture of neurotrophins to restore complete function. Transplantation of OEGs is a complicated process that requires the cells to be harvested in large numbers. Therefore, a less convoluted and perhaps less treacherous target would be the alteration the inhibitory environment of the damaged DREZ.

Damage to dorsal roots is not restricted to axons; glial cells within the spinal cord and the CNS-PNS interface (DREZ) proliferate and hypertrophy. As is the case within the CNS proper, a dynamic glial scar forms at the site of lesion, which proves impenetrable to regenerating axons (for review, see Aldskogius and Kozlova, 1998). However, in contrast to the CNS, the scar at the DREZ appears to be mostly astrocytic in nature and consequently rich in CSPGs (Beggah et al., 2005), therefore a target for ChABC digestion. Indeed, a recent study from Steinmetz et al. (2005) highlighted the efficacy of pharmacological delivery of ChABC in promoting functional regeneration of sensory neurons through the damaged DREZ. This study illustrated that ChABC injected directly into an injured dorsal root was capable of digesting CSPGs at the DREZ and throughout the dorsal horn.

In the current work, we found that the transgenic mice digest nearly all CSPG in the DREZ of a rhizotomized root. The transgenic digestion alone allows axonal regeneration and sensory recovery. In contrast, the ChABC pharmacological injection (Steinmetz et al., 2005) required a combination of ChABC and a potent inflammatory stimulus to achieve regeneration. Our transgenic study demonstrates the efficacy of ChABC to promote functional regeneration of rhizotomized sensory neurons even in the absence of additional manipulations to elevate their growth status. Indeed, all rhizotomized and regenerating axons in our study upregulated the growth-associated protein SPRR1A in the absence of additional stimuli. SPRR1A is a growth-associated intracellular protein known to be upregulated by damaged peripheral neurons (Bonilla et al., 2002).

The effects of transgenic ChABC on regeneration through the DREZ are not modality specific. One subset of SPRR1A-IR regenerating axons expresses the neuropeptide CGRP and is known to be nociceptive. Another subset of regenerating fibers can be transganglionically labeled with CTB and is known to mediate mechanoceptive and proprioceptive functions. Both CGRP-IR and CTB-IR axons regenerate through the damaged DREZ in rhizotomized Tg-ChABC mice. Although no aberrant growth of labeled axons or autotomy was observed in rhizotomized wildtype or transgenic mice, the early restoration of sensory function in the chronic Tg-ChABC: 3 and Tg-ChABC: 4 mice does not rule out the possibility that transgenic ChABC expression might enhance intraspinal reorganization of intact primary afferent terminals from adjacent spared dorsal roots. Intraspinal reorganization (Darian-Smith, 2004) and the emergence of thermal hyperalgesia (Abad et al., 1989; Ramer et al., 2004) are known to occur after partial brachial plexus deafferentation, and these factors may provide the recovery in nociceptive function observed in wild-type mice at the end of our testing period. However, mice from the acute groups clearly showed immediate sensory deficits and lack of regeneration in all genotypes; therefore, we conclude that recovery of thermal and mechanosensory function by $5 \mathrm{~d}$ in transgenic mice is attributable to regeneration through the dorsal root entry zone.

The current study emphasizes a key role for CSPGs in limiting axon growth in areas undergoing reactive astrogliosis. In contrast, parallel studies that interfere with myelin-associated inhibitors illustrate their effectiveness in areas more remote from the injury site. The divergent loci of action and the potency of both strategies suggest that a combinatorial approach targeting inhibitory extracellular matrix and myelin-associated inhibitors may be the most efficacious therapy to restore complex function to the damaged CNS.

\section{References}

Abad F, Feria M, Boada J (1989) Chronic amitriptyline decreases autotomy following dorsal rhizotomy in rats. Neurosci Lett 99:187-190.

Aldskogius H, Kozlova EN (1998) Central neuron-glial and glial-glial interactions following axon injury. Prog Neurobiol 55:1-26.

Asher RA, Morgenstern DA, Fidler PS, Adcock KH, Oohira A, Braistead JE, Levine JM, Margolis RU, Rogers JH, Fawcett JW (2000) Neurocan is upregulated in injured brain and in cytokine-treated astrocytes. J Neurosci 20:2427-2438.

Bareyre FM, Kerschensteiner M, Raineteau O, Mettenleiter TC, Weinmann O, Schwab ME (2004) The injured spinal cord spontaneously forms a new intraspinal circuit in adult rats. Nat Neurosci 7:269-277.

Barritt AW, Davies M, Marchand F, Hartley R, Grist J, Yip P, McMahon SB, Bradbury EJ (2006) Chondroitinase ABC promotes sprouting of intact and injured spinal systems after spinal cord injury. J Neurosci 26:10856-10867.

Bartsch U, Bandtlow CE, Schnell L, Bartsch S, Spillmann AA, Rubin BP, Hillenbrand R, Montag D, Schwab ME, Schachner M (1995) Lack of evidence that myelin-associated glycoprotein is a major inhibitor of axonal regeneration in the CNS. Neuron 15:1375-1381.

Basso DM, Fisher LC, Anderson AJ, Jakeman LB, McTigue DM, Popovich PG (2006) Basso Mouse Scale for locomotion detects differences in recovery after spinal cord injury in five common mouse strains. J Neurotrauma 23:635-659.

Beggah AT, Dours-Zimmermann MT, Barras FM, Brosius A, Zimmermann 
DR, Zurn AD (2005) Lesion-induced differential expression and cell association of Neurocan, Brevican, Versican V1 and V2 in the mouse dorsal root entry zone. Neuroscience 133:749-762.

Berry M, Maxwell WL, Logan A, Mathewson A, McConnell P, Ashhurst DE, Thomas GH (1983) Deposition of scar tissue in the central nervous system. Acta Neurochir Suppl (Wien) 32:31-53.

Bonilla IE, Tanabe K, Strittmatter SM (2002) Small proline-rich repeat protein $1 \mathrm{~A}$ is expressed by axotomized neurons and promotes axonal outgrowth. J Neurosci 22:1303-1315.

Bradbury EJ, Moon LD, Popat RJ, King VR, Bennett GS, Patel PN, Fawcett JW, McMahon SB (2002) Chondroitinase ABC promotes functional recovery after spinal cord injury. Nature 416:636-640.

Bregman BS, Kunkel-Bagden E, Schnell L, Dai HN, Gao D, Schwab ME (1995) Recovery from spinal cord injury mediated by antibodies to neurite growth inhibitors. Nature 378:498-501.

Brosamle C, Huber AB, Fiedler M, Skerra A, Schwab ME (2000) Regeneration of lesioned corticospinal tract fibers in the adult rat induced by a recombinant, humanized $\mathrm{IN}-1$ antibody fragment. J Neurosci 20:8061-8068.

Cafferty WB, Strittmatter SM (2006) The nogo-nogo receptor pathway limits a spectrum of adult CNS axonal growth. J Neurosci 26:12242-12250.

Caggiano AO, Zimber MP, Ganguly A, Blight AR, Gruskin EA (2005) Chondroitinase $\mathrm{ABCI}$ improves locomotion and bladder function following contusion injury of the rat spinal cord. J Neurotrauma 22:226-239.

Darian-Smith C (2004) Primary afferent terminal sprouting after a cervical dorsal rootlet section in the macaque monkey. J Comp Neurol 470:134-150.

Davies SJ, Fitch MT, Memberg SP, Hall AK, Raisman G, Silver J (1997) Regeneration of adult axons in white matter tracts of the central nervous system. Nature 390:680-683.

Davies SJ, Goucher DR, Doller C, Silver J (1999) Robust regeneration of adult sensory axons in degenerating white matter of the adult rat spinal cord. J Neurosci 19:5810-5822.

Dergham P, Ellezam B, Essagian C, Avedissian H, Lubell WD, McKerracher L (2002) Rho signaling pathway targeted to promote spinal cord repair. J Neurosci 22:6570-6577.

Dimou L, Schnell L, Montani L, Duncan C, Simonen M, Schneider R, Liebscher T, Gullo M, Schwab ME (2006) Nogo-A-deficient mice reveal strain-dependent differences in axonal regeneration. J Neurosci 26:5591-5603.

Fitch MT, Silver J (1997) Glial cell extracellular matrix: boundaries for axon growth in development and regeneration. Cell Tissue Res 290:379-384.

Fitch MT, Doller C, Combs CK, Landreth GE, Silver J (1999) Cellular and molecular mechanisms of glial scarring and progressive cavitation: in vivo and in vitro analysis of inflammation-induced secondary injury after CNS trauma. J Neurosci 19:8182-8198.

Fouad K, Klusman I, Schwab ME (2004) Regenerating corticospinal fibers in the Marmoset (Callitrix jacchus) after spinal cord lesion and treatment with the anti-Nogo-A antibody IN-1. Eur J Neurosci 20:2479-2482.

Fournier AE, Gould GC, Liu BP, Strittmatter SM (2002) Truncated soluble Nogo receptor binds Nogo-66 and blocks inhibition of axon growth by myelin. J Neurosci 22:8876-8883.

GrandPre T, Li S, Strittmatter SM (2002) Nogo-66 receptor antagonist peptide promotes axonal regeneration. Nature 417:547-551.

Harel NY, Strittmatter SM (2006) Can regenerating axons recapitulate developmental guidance during recovery from spinal cord injury? Nat Rev Neurosci 7:603-616.

Houle JD, Tom VJ, Mayes D, Wagoner G, Phillips N, Silver J (2006) Combining an autologous peripheral nervous system "bridge" and matrix modification by chondroitinase allows robust, functional regeneration beyond a hemisection lesion of the adult rat spinal cord. J Neurosci 26:7405-7415.

Htut M, Misra P, Anand P, Birch R, Carlstedt T (2006) Pain phenomena and sensory recovery following brachial plexus avulsion injury and surgical repairs. J Hand Surg [Br] 31:596-605.

Johnson WB, Ruppe MD, Rockenstein EM, Price J, Sarthy VP, Verderber LC, Mucke L (1995) Indicator expression directed by regulatory sequences of the glial fibrillary acidic protein (GFAP) gene: in vivo comparison of distinct GFAP-lacZ transgenes. Glia 13:174-184.

Kim JE, Li S, GrandPre T, Qiu D, Strittmatter SM (2003) Axon regeneration in young adult mice lacking Nogo-A/B. Neuron 38:187-199.
Kim JE, Liu BP, Park JH, Strittmatter SM (2004) Nogo-66 receptor prevents raphespinal and rubrospinal axon regeneration and limits functional recovery from spinal cord injury. Neuron 44:439-451.

Levine JM (1994) Increased expression of the NG2 chondroitin-sulfate proteoglycan after brain injury. J Neurosci 14:4716-4730.

Li S, Strittmatter SM (2003) Delayed systemic Nogo-66 receptor antagonist promotes recovery from spinal cord injury. J Neurosci 23:4219-4227.

Li S, Liu BP, Budel S, Li M, Ji B, Walus L, Li W, Jirik A, Rabacchi S, Choi E, Worley D, Sah DW, Pepinsky B, Lee D, Relton J, Strittmatter SM (2004) Blockade of nogo-66, myelin-associated glycoprotein, and oligodendrocyte myelin glycoprotein by soluble nogo-66 receptor promotes axonal sprouting and recovery after spinal injury. J Neurosci 24:10511-10520.

Li S, Kim JE, Budel S, Hampton TG, Strittmatter SM (2005) Transgenic inhibition of Nogo-66 receptor function allows axonal sprouting and improved locomotion after spinal injury. Mol Cell Neurosci 29:26-39.

Li W, Walus L, Rabacchi SA, Jirik A, Chang E, Schauer J, Zheng BH, Benedetti NJ, Liu BP, Choi E, Worley D, Silvian L, Mo W, Mullen C, Yang W, Strittmatter SM, Sah DW, Pepinsky B, Lee DH (2004) A neutralizing anti-Nogo66 receptor monoclonal antibody reverses inhibition of neurite outgrowth by central nervous system myelin. J Biol Chem 279:43780-43788.

Liu BP, Cafferty WB, Budel SO, Strittmatter SM (2006) Extracellular regulators of axonal growth in the adult central nervous system. Philos Trans R Soc Lond B Biol Sci 361:1593-1610.

McGee AW, Strittmatter SM (2003) The Nogo-66 receptor: focusing myelin inhibition of axon regeneration. Trends Neurosci 26:193-198.

McKeon RJ, Hoke A, Silver J (1995) Injury-induced proteoglycans inhibit the potential for laminin-mediated axon growth on astrocytic scars. Exp Neurol 136:32-43.

Pezet S, McMahon SB (2006) Neurotrophins: mediators and modulators of pain. Annu Rev Neurosci 29:507-538.

Ramer LM, Borisoff JF, Ramer MS (2004) Rho-kinase inhibition enhances axonal plasticity and attenuates cold hyperalgesia after dorsal rhizotomy. J Neurosci 24:10796-10805.

Ramer MS, Priestley JV, McMahon SB (2000) Functional regeneration of sensory axons into the adult spinal cord. Nature 403:312-316.

Ramon-Cueto A, Cordero MI, Santos-Benito FF, Avila J (2000) Functional recovery of paraplegic rats and motor axon regeneration in their spinal cords by olfactory ensheathing glia. Neuron 25:425-435.

Romero MI, Rangappa N, Garry MG, Smith GM (2001) Functional regeneration of chronically injured sensory afferents into adult spinal cord after neurotrophin gene therapy. J Neurosci 21:8408-8416.

Schnell L, Schwab ME (1990) Axonal regeneration in the rat spinal cord produced by an antibody against myelin-associated neurite growth inhibitors. Nature 343:269-272.

Simonen M, Pedersen V, Weinmann O, Schnell L, Buss A, Ledermann B, Christ F, Sansig G, van der Putten H, Schwab ME (2003) Systemic deletion of the myelin-associated outgrowth inhibitor Nogo-A improves regenerative and plastic responses after spinal cord injury. Neuron 38:201-211

Steinmetz MP, Horn KP, Tom VJ, Miller JH, Busch SA, Nair D, Silver DJ, Silver J (2005) Chronic enhancement of the intrinsic growth capacity of sensory neurons combined with the degradation of inhibitory proteoglycans allows functional regeneration of sensory axons through the dorsal root entry zone in the mammalian spinal cord. J Neurosci 25:8066-8076.

Tang X, Davies JE, Davies SJ (2003) Changes in distribution, cell associations, and protein expression levels of NG2, neurocan, phosphacan, brevican, versican $\mathrm{V} 2$, and tenascin-C during acute to chronic maturation of spinal cord scar tissue. J Neurosci Res 71:427-444.

Yick LW, Wu W, So KF, Yip HK, Shum DK (2000) Chondroitinase ABC promotes axonal regeneration of Clarke's neurons after spinal cord injury. NeuroReport 11:1063-1067.

Zheng B, Ho C, Li S, Keirstead H, Steward O, Tessier-Lavigne M (2003) Lack of enhanced spinal regeneration in Nogo-deficient mice. Neuron 38:213-224.

Zheng B, Atwal J, Ho C, Case L, He XL, Garcia KC, Steward O, TessierLavigne M (2005) Genetic deletion of the Nogo receptor does not reduce neurite inhibition in vitro or promote corticospinal tract regeneration in vivo. Proc Natl Acad Sci USA 102:1205-1210. 